\title{
Bulk Metallic Glasses: Overcoming the Challenges to Widespread Applications
}

\author{
Peter K. Liaw, Gongyao Wang, and Judy Schneider
}

Since an amorphous solid was first synthesized by rapidly quenching with cooling rates up to $10^{6} \mathrm{~K} / \mathrm{s},{ }^{1}$ the formation, structure, and property studies of metallic glasses have attracted increasing attention because of their fundamental scientific importance and engineering application potentials. New multicomponent glassy-alloy systems with lower critical cooling rates, such as $\mathrm{Zr}-\mathrm{Cu}-\mathrm{Ni}, \mathrm{Zr}-\mathrm{Cu}-\mathrm{Ni}-\mathrm{Al}$, and $\mathrm{Zr}-\mathrm{Ti}-\mathrm{Cu}-\mathrm{Ni}-\mathrm{Be}$ were discovered in the 1990s. ${ }^{2-4}$ Now amorphous alloys can be fabricated into bulk forms ranging from several millimeters to several centimeters in thickness. Therefore, "bulk metallic glasses" (BMGs) is the name commonly used for these glassy metals. In addition, BMG composites were developed by introducing specific crystalline phases in an amorphous matrix to improve plasticity and toughness, which could broaden BMG applications. ${ }^{5,6}$

In general, BMGs exhibit many desirable properties: high strength, high hardness, excellent elasticity, low coefficients of friction, near-net-shape casting, and almost perfect as-cast surfaces. ${ }^{4}$ As excellent candidates for structural materials, BMGs have been applied to new industrial products requiring high performance, such as microgears, casings for electronic products, and golfclub heads. ${ }^{4}$ To apply BMGs extensively, critical issues need to be solved.

First, BMGs usually lack ductility. The deformation and fracture behaviors of BMGs at room temperature are controlled by the initiation and propagation of shear bands, which result in the limited global deformation of about $2 \%$, particularly under tensile deformations. ${ }^{7}$ It is important to understand the relationship between the ductility and atomic microstructure in BMGs.
Second, size effects in BMGs are interesting. ${ }^{9}$ The mechanical behaviors of metallic glasses during bending, compression, tensile, impact, and fatigue exhibit variations with the specimen geometry. ${ }^{10,11}$ Thus, the constraint of shear-band formation and deformation processes is critical to elucidate these phenomena. Third, understanding of the fatigue behavior of BMGs is limited. ${ }^{12-14}$ BMGs can exhibit a wide range of fatigue properties. Moreover, the characteristic for the formation of shear bands is unknown during cyclic deformation of metallic glasses, which raises additional questions: When and how will shear bands form? How does the fatigue crack initiate and propagate in metallic glasses? Another challenge is the fabrication of high-quality and large-size samples. Some good glass-forming alloys involve the use of elements that are either expensive or difficult to handle safely (such as beryllium ${ }^{3}$ ). However, with the development of alloys that are based on less expensive elements and more tolerant of impurities, the cost of BMGs will continue to decline relative to other high-performance alloys, ${ }^{4}$ and high-quality and large-size samples will become available. Finally, applications of BMGs are very few. Thus, how to find new applications for BMGs is pertinent for continued research activities of BMGs.

This JOM topic on BMGs presents discussions and developments related to the above questions. Due to the extent of the information available, four articles will be presented in this issue; another three will be published in April. The following papers are in this issue.

"Understanding the Properties and Structure of Metallic Glasses at the Atomic Level" by T. Egami reviews the behavior of glasses and liquids at the atomic level and the microscopic mechanisms that control the properties of metallic glasses.

In "Mechanical Response of Metallic Glasses: Insights from In-situ High Energy X-ray Diffraction," Mihai Stoica et al. review the use of the synchrotron radiation to evaluate the elastic-plastic response of BMGs.

"Amorphous Metals for Hard-tissue Prosthesis" by Marios D. Demetriou et al. reviews the performance of amorphous alloys relevant to hard-tissue prosthesis.

"Metallic Glasses: Gaining Plasticity for Microsystems" by Yong Yang et al. summarizes the experimental findings related to size effects on plasticity in metallic glasses.

\section{References}

1. W. Klement, R. H. Willens, and P. Duwez, Nature, 187 (1960), p. 869.

2. A. Inoue, Acta Mater., 48 (2000), p. 279.

3. A. Peker and W.L. Johnson, Applied Physics Letters, 63 (1993), p. 2342.

4. M.K. Miller and P.K. Liaw, editors, Bulk Metallic Glasses (New York: Springer, 2007).

5. D.C. Hofmann et al., Nature, 451 (2008), p. 1085

6. J.W. Qiao et al., Applied Physics Letters, 94 (2009), 151905.

7. W.J. Wright, R. Saha, and W.D. Nix, Mater. Trans., 42 (2001), p. 642.

8. J. Schroers and W.L. Johnson, Phys. Rev. Lett., 93 (2004), 255506.

9. R.D. Conner et al., Acta Materialia, 52 (2004), p. 2429.

10. F.X. Liu et al., Intermetallics, 14 (2006), p. 1014.

11. H. Guo et al., Nature Materials, 6 (2007), p. 735.

12. C.J. Gillbert, V. Schroeder, and R.O. Ritchie, Metallurgical and Materials Transactions A, 30A (1999), p. 1739.

13. B.C. Menzel and R.H. Dauskardt, Acta Mater., 54 (2006), p. 935.

14. G.Y. Wang et al., Mater. Sci. and Eng., 494 (2008), p. 314 .

Peter K. Liaw and Gongyao Wang are with the Department of Materials Science and Engineering, The University of Tennessee, Knoxville, TN 37996; and Judy Schneider is with the Mechanical Engineering Department, Mississippi State University, MS. Dr. Schneider is the JOM advisor from the Mechanical Behavior of Materials Committee of the TMS Structural Materials Division. 